\title{
POLÍTICAS LINGUIISTICAS DO ESTADO NOVO E BIOPODER: A QUESTÃO DAS LÍNGUAS DE IMIGRANTES ITALIANOS EM SANTA CATARINA
}

\author{
LANGUAGE POLICIES OF THE ESTADO NOVO AND BIOPOWER: \\ THE ISSUE OF THE LANGUAGES OF ITALIAN IMMIGRANTS IN SANTA \\ CATARINA
}

Renata Santos

Universidade Federal de Santa Catarina, Florianópolis Santa Catarina, Brasil

renatasantosb@yahoo.com.br

\begin{abstract}
Resum0: Este artigo apresenta uma leitura das políticas linguísticas do Estado Novo, e seus mecanismos de controle, especialmente no que tange as línguas italianas faladas por imigrantes italianos e seus descendentes em Santa Catarina, a partir do conceito de biopolítica (FOUCAULT, 2005). Dentro do projeto de nacionalização promovido pelo Estado Novo, criouse a imagem de um inimigo comum, o estrangeiro, e uma das políticas postas em ação era a interdição das línguas estrangeiras. O que este trabalho discute é como se dá a interferência do Estado não apenas por meio das leis, mas a partir de mecanismos de controle e vigilância que se espraiam por entre os indivíduos, seguindo a lógica do panóptico (FOUCAULT, 1987), a partir da qual o poder incide diretamente sobre os corpos produzindo corpos dóceis. No caso dos imigrantes italianos em Santa Catarina, essas políticas resultaram no apagamento de várias línguas italianas trazidas pelos imigrantes, além do desenvolvimento de uma conotação negativa para o termo "colono", que perdura até os dias atuais e contribuiu para a construção de uma imagem negativa sobre os descendentes de imigrantes italianos.

Palavras-chave: Políticas Linguísticas; Biopoder; Língua Italiana; Imigração
\end{abstract}

Abstract: The present article discusses the linguistic policies of the Estado Novo (New State) and its control mechanisms, especially with regards to the Italian languages spoken by Italian immigrants and their descendants in Santa Catarina, based on the perspective of the concept of Biopolitics (FOUCAULT, 2005). The project of nationalization developed by Estado Novo has created the image of a common enemy, the foreigner, and one of the policies applied during that time was the foreign languages prohibition. This paper aims to show how the State intervenes not only with the creation of laws, but also by means of control and surveillance mechanisms that spread among individuals, according to the logic of panopticon (FOUCAULT, 1987), which argues that the power directly affects the bodies and produces docile bodies. In the case of the Italian immigrants in Santa Catarina, these policies resulted in the disappearance of several Italian languages brought by immigrants. Furthermore, an enduring negative connotation of the term "colono" was developed, which contributed to the negative image on the descendants of Italian immigrants.

Keywords: Language Policies; Biopower; Italian Language; Immigration

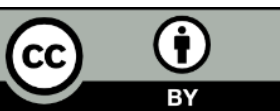




\section{INTRODUÇÃO}

Neste artigo proponho uma leitura das políticas linguísticas do Estado Novo, e seus mecanismos de controle, especialmente no que tange às línguas italianas faladas por imigrantes italianos e seus descendentes em Santa Catarina, a partir do conceito de biopolítica (FOUCAULT, 2005). De acordo com Foucault, a biopolítica, ou biopoder, é uma tecnologia do poder que incide sobre os corpos com o intuito de intervir não apenas naquilo que é da ordem do indivíduo, mas também no corpo social, nos fenômenos naquilo que eles têm de global. Desse modo, a noção de população ${ }^{1}$ é aquilo com que a biopolítica vai lidar.

\footnotetext{
Não se trata, por conseguinte, em absoluto, de considerar o indivíduo no nível do detalhe, mas, pelo contrário, mediante mecanismos globais, de agir de tal maneira que se obtenham estados globais de equilíbrio, de regularidade; em resumo, de levar em conta a vida, os processos biológicos do homem-espécie e de assegurar sobre eles não uma disciplina, mas uma regulamentação. (FOUCAULT, 2005, p. 294)
}

No caso dos imigrantes e seus descendentes, seus corpos passam a estar sob o controle do Estado, é o Estado que vai deliberar sobre esses corpos na medida em que regulamenta que língua devem falar, que tipo de escola seus filhos devem frequentar, que atividades de lazer podem exercer, a que serviços públicos terão acesso e sob quais condições. Para a manutenção desse controle, entram em ação diversos mecanismos de poder. O poder, neste caso, não é entendido como uma propriedade, ninguém detém o poder, este é, sim, entendido como uma função (FOUCAULT, 2009b) que passa pelos corpos, por todos os extratos sociais, não é apenas vertical, do Estado para o povo, é difuso, atua em várias direções, não se trata apenas do Estado atuando sobre os indivíduos, mas dos próprios indivíduos atuando sobre os indivíduos.

Assim, o trabalho se divide em três partes: i) referencial teórico; ii) políticas linguísticas do Estado Novo; iii) discussão das implicações das políticas linguísticas do Estado Novo para os imigrantes italianos em Santa Catarina.

\section{REFERENCIAL TEÓRICO}

A biopolítica, segundo Foucault, é um poder de fazer viver, é o direito de intervir para fazer viver, "e na maneira de viver, e no 'como' da vida, a partir do momento em que, portanto, o poder intervém sobretudo nesse nível para aumentar a vida" (FOUCAULT, 2005, p. 295). Ao apontar as possíveis limitações do biopoder (uma vez que o biopoder é um poder sobre a vida, como pode também matar?), Foucault aponta o racismo como uma "emergência" do biopoder, pois o racismo representa "o corte entre o que deve viver e o que deve morrer" (FOUCAULT, 2005 , p. 304). Ao dividir o corpo social em subgrupos são feitas as cesuras necessárias no interior do contínuo biológico sobre o qual o biopoder incide.

Por isso é comum relacionar a biopolítica ao nazismo, no sentido do controle do Estado sobre o corpo e o estabelecimento da vida a partir da morte. Segundo Foucault, esse jogo do nazismo está inscrito no funcionamento de todos os Estados: "apenas o nazismo, é claro, levou até o paroxismo o jogo entre o direito soberano de matar e os mecanismos do biopoder. Mas tal jogo está efetivamente inscrito no funcionamento de todos os Estados" (FOUCAULT, 2005, p. 312).

\footnotetext{
1 “É um novo corpo: corpo múltiplo, corpo com inúmeras cabeças [...]” (FOUCAULT, 2005, p. 292)
} 
Para Foucault, o corpo é entendido como um lugar sobre o qual o poder incide. Esse poder que atua sobre o corpo pode ser entendido também como "uma tomada de poder sobre o homem enquanto ser vivo, uma espécie de estatização do biológico" (FOUCAULT, 2005, p. 286). Um dos mecanismos que incide sobre o corpo é o panóptico, um dispositivo, uma técnica que muda o jeito de as pessoas pensarem o sujeito, é uma metáfora da sociedade de vigilância: "é uma maneira de fazer funcionar relações de poder numa função, e uma função para essas relações de poder" (FOUCAULT, 1987, p. 196).

No caso do panóptico há uma sujeição real e uma sujeição fictícia, isto é, a vigilância é real, mesmo que às vezes fictícia, no sentido de que o sujeito não está sendo vigiado de fato, no entanto a possibilidade de vigilância é real. O poder do panóptico é invisível, incorpóreo, mas com efeitos profundos, é um dispositivo que "desindividualiza o poder":

há uma maquinaria que assegura a dissimetria, o desequilíbrio, a diferença. Pouco importa, consequentemente, quem exerce o poder. Um indivíduo, quase tomado ao acaso, pode fazer funcionar a máquina [...]. Quanto mais numerosos esses observadores anônimos e passageiros, tanto mais aumentam para o prisioneiro o risco de ser surpreendido e a consciência inquieta de ser observado. (FOUCAULT, 1987, p. 167)

Justamente por ser incorpóreo é mais funcional, menos dispendioso, gera mais poder, se espalha para todos os lugares/espaços. Ainda assim o poder incide diretamente sobre o corpo, não é apenas um mecanismo de vigilância, é um poder sobre a vida (diferentemente do poder soberano, que era um poder de morte) a serviço da produção de corpos dóceis.

Segundo Foucault, "é dócil o corpo que pode ser submetido, que pode ser utilizado, que pode ser transformado e aperfeiçoado" (FOUCAULT, 1987, p. 118). A disciplina, a partir da ideia de disciplina militar, é uma tecnologia para criar pessoas dóceis, obedientes, mais do que obedecer às leis e sujeitar os corpos, trata-se de tornar os corpos mais úteis, produtivos. Foucault explica que essa mecânica do poder "define como se pode ter domínio sobre o corpo dos outros, não simplesmente para que façam o que se quer, mas para que operem como se quer, com as técnicas, segundo a rapidez e a eficácia que se determina" (FOUCAULT, 1987, p. 119).

O adestramento dos corpos é uma tecnologia (modo de fazer) que começa na prisão e se estende para outros lugares, como as igrejas, as escolas, por exemplo, ensina-se uma ortodoxia para criar corpos dóceis. Há uma estatização dos mecanismos de controle, como a polícia, por exemplo, contudo há também uma deflagração ubíqua do poder policial: há a polícia do soberano (polícia estatal) e a polícia do povo (qualquer um pode denunciar seu vizinho).

O biopoder age, portanto, sob vários aspectos da vida humana, inclusive sobre a linguagem. Exemplo de ação de controle sobre as línguas são as políticas linguísticas aventadas pelo Estado Novo, em especial a proibição do uso de línguas estrangeiras nas esferas públicas e privadas. A seguir serão apresentadas as políticas linguísticas do Estado Novo, seus mecanismos de controle e regulamentação, e sua relação com a biopolítica.

\section{POLÍTICAS LINGUÍSTICAS DO ESTADO NOVO PARA UM PROJETO DE NACIONALIZAÇÃO}

Durante o período do Estado Novo (1937 - 1946) surgem preocupações a respeito do uso da língua dos países de origem dos imigrantes e seus descendentes, sobretudo alemães e 
italianos, seja no âmbito privado, seja no público, com especial preocupação com as escolas ${ }^{2}$ mantidas pelos imigrantes e seus descendentes.

De acordo com Campos (2006), a regulamentação, por meio de legislação, da língua nacional serviu para enfatizar que essa regulamentação não foi aceita com facilidade pelas populações às quais se destinava. Assim, vieram as práticas interventoras, com o intuito de modificar não apenas aquilo que correspondia à vida pública da população, mas também à vida privada: "[...] essa prática passou pelo refazer de hábitos e condutas, elementares nas relações pessoais, na sociedade local, bem como pela transformação dos indivíduos em trabalhadores brasileiros" (CAMPOS, 2006, p. 19). Esse projeto nacionalista atingiu diversas instituições, desde a família, até a escola e os espaços de trabalho, com o intuito de conformar os estrangeiros (imigrantes e seus descendentes) a aspectos de brasilidade que constituíam uma identidade nacional homogênea. Essa homogeneidade, cultivada pelas políticas nacionalistas do Estado Novo, encontrou na diversidade cultural e linguística dos imigrantes e seus descendentes um conflito. Foi assim que paradoxalmente, segundo a autora,

[...] o Estado getulista perseguiu certos segmentos como inimigos da nação, acusando parte dos descendentes de imigrantes alemães de nazistas, mas ao mesmo tempo adotou métodos muito semelhantes àqueles vigentes na Alemanha no mesmo período. (CAMPOS, 2006, p. 20).

Dentre as políticas do Estado Novo que incidiram sobre a língua e os imigrantes, são destacadas no quadro 1 algumas que podem servir para ilustrar seu cunho biopolítico, tendo em vista seu caráter de racialização (por meio da separação da população entre brasileiros e estrangeiros $^{3}$, estes apresentados como uma ameaça à constituição nacional), bem como os mecanismos de controle (censura, proibição da formação de núcleos estrangeiros e mesmo da veiculação de publicações em línguas estrangeiras).

Quadro 1 - Legislação do Estado Novo sobre a língua e os emigrantes

\begin{tabular}{ll}
\multicolumn{1}{c}{ Decreto } & \multicolumn{1}{c}{ Trata de } \\
\hline $\begin{array}{l}\text { Decreto } n^{\circ} \text { 20.108 } \\
\text { de 1931. }\end{array}$ & $\begin{array}{l}\text { Simplificação da ortografia, por meio de acordo feito com Portugal, e } \\
\text { regulamentação de seu uso no país. }\end{array}$ \\
\hline $\begin{array}{l}\text { Decreto-Lei } n^{\circ} 93 \\
\text { de 1937. }\end{array}$ & $\begin{array}{l}\text { Criação do Instituto Nacional do Livro com objetivo de: baratear a edição de } \\
\text { livros no país; custear bibliotecas públicas; organizar e publicar uma } \\
\text { "Enciclopédia Brasileira" e um "Dicionário da Língua Nacional". }\end{array}$ \\
\hline $\begin{array}{l}\text { Decreto-Lei } n^{\circ} 25 \\
\text { de 1937. }\end{array}$ & $\begin{array}{l}\text { Regulamentação da organização e proteção do patrimônio histórico e artístico } \\
\text { nacional. }\end{array}$ \\
\hline $\begin{array}{l}\text { Decreto-Lei } n^{\circ} 383 \\
\text { de 1938. }\end{array}$ & $\begin{array}{l}\text { Proibição da criação, organização ou manutenção, por parte de estrangeiros, de } \\
\text { associações de caráter político. } \\
\text { Associações culturais (o que incluía as escolas) não poderiam receber auxílios } \\
\text { de governos estrangeiros ou de pessoas domiciliadas no exterior. }\end{array}$ \\
\hline
\end{tabular}

\footnotetext{
${ }^{2}$ A imigração italiana no Brasil, que ocorreu principalmente nas duas últimas décadas do século XIX, teve como característica uma forte preocupação com a religião e educação. Nas primeiras décadas do século XX havia, nas comunidades de imigrantes italianos, escolas organizadas e mantidas pelos próprios imigrantes e seus descendentes, muitas vezes recebendo inclusive subsídios do Governo italiano. Essas escolas foram completamente extintas durante o período do Estado Novo (VIRTUOSO; RABELO, 2015).

${ }^{3}$ Estrangeiros eram todos aqueles que, embora vivessem no Brasil, não tinham nacionalidade brasileira ou eram descendentes de estrangeiros.
} 


\begin{tabular}{|c|c|}
\hline & $\begin{array}{l}\text { Era proibido manter publicações de qualquer natureza com objetivos políticos, } \\
\text { permitindo ao governo interditar sedes onde aconteciam atividades políticas, } \\
\text { bem como fechar gráficas e jornais. }{ }^{4}\end{array}$ \\
\hline $\begin{array}{l}\text { Decreto-Lei } n^{\circ} 389 \\
\text { de } 1938 .\end{array}$ & $\begin{array}{l}\text { Regulamentação da nacionalidade brasileira, sendo o conhecimento da língua } \\
\text { portuguesa uma condição para sua obtenção. A dupla nacionalidade não era } \\
\text { permitida, e estrangeiros que não regularizassem sua nacionalidade brasileira } \\
\text { poderiam ser presos ou expulsos do país. Era permitido ao governo revogar os } \\
\text { direitos de quem exercesse atividade política ou social nociva ao interesse } \\
\text { nacional. }\end{array}$ \\
\hline $\begin{array}{l}\text { Decreto-Lei } n^{\circ} 406 \\
\text { de } 1938 .\end{array}$ & $\begin{array}{l}\text { Regulamentação da entrada e permanência de estrangeiros no Brasil. } \\
\text { Tornou-se obrigatório o ensino de qualquer matéria em língua portuguesa, bem } \\
\text { como o ensino de história e geografia brasileiras em todas as instituições de } \\
\text { ensino. Proibiu-se o ensino de idiomas estrangeiros a menores de quatorze anos. } \\
\text { Instituiu-se que as escolas fossem regidas por brasileiros natos, e que os livros } \\
\text { escolares fossem escritos exclusivamente em língua portuguesa. }\end{array}$ \\
\hline $\begin{array}{l}\text { Decreto } n^{\circ} 3.010 \text { de } \\
1938\end{array}$ & $\begin{array}{l}\text { Proibição da constituição de núcleos de estrangeiros de uma mesma } \\
\text { nacionalidade e da atribuição de nomes estrangeiros a sociedades e } \\
\text { estabelecimentos comerciais ou industriais. } \\
\text { Foi criado o Conselho de Imigração e Colonização. }\end{array}$ \\
\hline $\begin{array}{l}\text { Decreto-Lei } n . \\
1.915 \text { de } 1939 .\end{array}$ & $\begin{array}{l}\text { Criação do Departamento de Imprensa e Propaganda (D.I.P.), cujas funções } \\
\text { incluíam coordenar a propaganda nacional, fazer censura do teatro, cinema, } \\
\text { literatura, rádio e imprensa, e incentivo à arte e literatura genuinamente } \\
\text { brasileiras, enquanto proibia publicações estrangeiras nocivas aos interesses } \\
\text { brasileiros. }\end{array}$ \\
\hline $\begin{array}{l}\text { Decreto } n^{\circ} 5.077 \text { de } \\
1939 .\end{array}$ & $\begin{array}{l}\text { Instituição da obrigatoriedade da "Hora do Brasil”" no espaço radiofônico, e a } \\
\text { proibição de transmissões de rádios estrangeiras. }\end{array}$ \\
\hline $\begin{array}{l}\text { Decreto-Lei } n^{o} \\
3.119 \text { de } 1941 .\end{array}$ & $\begin{array}{l}\text { Criação da "Juventude Brasileira", instituição nacional cujo objetivo era } \\
\text { promover a educação moral e cívica da juventude, dentro e fora da escola. Entre } \\
\text { suas atividades estava o culto à bandeira e cantar o hino nacional. }\end{array}$ \\
\hline $\begin{array}{l}\text { Decreto } n^{\circ} 11.491 \\
\text { de } 1943 .\end{array}$ & $\begin{array}{l}\text { Implementação, pelo Ministério da Educação e Saúde, do Serviço de } \\
\text { Radiodifusão Educativa, cujo objetivo era auxiliar na educação promovendo } \\
\text { programas científicos, literários e artísticos, e informando a respeito da política } \\
\text { de educação no país. }\end{array}$ \\
\hline
\end{tabular}

Fonte: baseado em Campos (2006).

Dentre as políticas listadas acima, é possível perceber um forte caráter de controle, sobretudo em relação ao que era estrangeiro (desde pessoas até palavras), pois o estrangeiro era considerado uma ameaça à nação, mais especificamente ao projeto de nacionalização do governo. As políticas linguísticas são várias, vão desde a regulamentação do acordo ortográfico que passou a vigorar na impressa e nas repartições públicas, até a proibição de palavras estrangeiras (como nomes de comércios), passando principalmente pela nacionalização do ensino (escolas brasileiras, com professores brasileiros ministrando aulas em língua portuguesa, ensinando história e geografia brasileiras).

A questão linguística era estratégica naquele momento, era essencial para a constituição do nacionalismo do Estado Novo que o uso da língua portuguesa fosse difundido no país inteiro, inclusive nas regiões de "colonização estrangeira". Sendo assim, principalmente a partir da década de 1940, o discurso até então sustentado pelo governo e imigrantes estrangeiros cedeu espaço a uma valorização dos costumes nacionais. Essa valorização se dava a partir do trabalho, porém não mais o trabalho disciplinado do estrangeiro, o qual não fazia

\footnotetext{
${ }^{4}$ Em consonância com a política nacional, A Secretaria de Segurança Pública de Santa Catarina criou o Serviço de Estrangeiros, cuja finalidade era fiscalizar a permanência dos estrangeiros em território nacional. (Decreto-Lei no 239, de 1938.)
} 
sentido valorizar; reconfigurou-se, então, o discurso do trabalho, era preciso "resgatar o trabalhador nacional".

A preocupação do Estado com essas populações pode ser explicada também a partir do que Foucault apresenta em "A Governamentabilidade": uma mudança na forma de governar, se antes o objetivo do Estado era manter o seu território, agora mais que isso a população também é objetivo,

[...] a população aparecerá como o objetivo final do governo. Pois qual pode ser o objetivo do governo? Não certamente governar, mas melhorar a sorte da população, aumentar sua riqueza, sua duração de vida, sua saúde, etc. E quais são os instrumentos que o governo utilizará para alcançar estes fins, que em certo sentido são imanentes à população? Campanhas, através das quais se age diretamente sobre a população, e técnicas que vão agir indiretamente sobre ela e que permitirão aumentar, sem que as pessoas se dêem conta, a taxa de natalidade ou dirigir para uma determinada região ou para uma determinada atividade os fluxos de população, etc. (FOUCAULT, 2009b, p. 170)

Governo e biopolítica são coisas que caminham juntas, o fim agora não é apenas a manutenção do Estado, mas múltiplas finalidades, no caso específico do Estado Novo tinha importância também a construção de um ideal de nacionalidade. Como uma característica da ciência de governar, o governo passa a ser paciente, não é mais o soberano que tem poder de morte, mas aquele que cuida. É desse modo, cuidando da população (FOUCAULT, 2009b, p. 170), que Getúlio Vargas regulamenta, por exemplo, a nacionalidade brasileira, garantindo aos estrangeiros direitos e garantindo aos brasileiros sua segurança frente às ameaças representadas pelos estrangeiros.

Campos (2006) destaca também as publicações onde eram veiculados artigos sobre estrangeiros no Brasil, realizando estudos sobre seus hábitos, os quais apontavam recorrentemente a dispersão e o isolacionismo dos imigrantes, que eram vistos como motivo de preocupação por parte do Estado. A autora também aponta um crescimento no número de trabalhos de geografia e das publicações do IBGE, as quais, especialmente no Sul "preocupavam-se em levantar o número de estrangeiros e seus descendentes e as populações que não falavam a língua nacional, numa clara manifestação da necessidade de conhecer para intervir e de saber para produzir textos de intervenção" (CAMPOS, 2006, p. 136). Estatística é um discurso, uma técnica biopolítica de governo, produzido para alimentar o próprio governo, pois, como já apontado, a população vai ser o objetivo central do governo, que vai produzir saberes sobre a população para poder intervir sobre ela.

Além de produzir conhecimento para o Estado, a geografia estatística se torna um discurso em prol da consolidação de determinado projeto nacional, especialmente quando associada ao projeto de nacionalização ${ }^{5}$ do ensino, que fez com que mais pessoas tivessem acesso a essas informações.

\section{CENÁRIO CATARINENSE: IMIGRANTES ITALIANOS E AS POLÍTICAS LINGUÍSTICAS DO ESTADO NOVO}

\footnotetext{
${ }^{5}$ Aqui é relevante também destacar o papel desempenhado pela radiodifusão, em especial as transmissões da "Hora do Brasil" e do "Serviço de Radiodifusão Educativa", ambos criados pelo governo e geridos pelo DIP com o intuito de promover o projeto de nação defendido pelo governo e garantir, para o mesmo fim, a difusão da língua portuguesa.
} 
Quanto ao cenário catarinense, Campos (2006) aponta que as intervenções do Estado ocorreram não apenas por meio de textos (propagandas), mas também por ataques a certas zonas de Santa Catarina, não só por conta da ameaça que a autonomia das instituições geridas por imigrantes e seus descendentes representava, mas também porque alguns núcleos se constituíam como polos econômicos importantes. De acordo com a autora, entre os imigrantes se organizavam autonomamente as instituições, isto é, se organizavam independentemente do Estado, era comum que se reunissem em mutirão para construir estradas, escolas e capelas. Além disso, as organizações para as atividades de lazer também eram geridas pelos imigrantes e posteriormente seus descendentes, o que também favoreceu a manutenção de suas tradições, levando maiores preocupações para o projeto hegemônico de Vargas:

preocupações a respeito de possibilidades de formação de cistos raciais, grupos linguísticos, vinculações com o estrangeiro, desrespeito a medidas de caráter nacional e separatismos levaram os governos federal e estadual a intervir nas regiões em que se concentravam núcleos de imigrantes estrangeiros e seus descendentes. (CAMPOS, 2006, p. 103)

Além das propagandas a respeito de um inimigo comum manifesto na imagem dos estrangeiros (imigrantes e seus descendentes) que mantinham autonomamente as tradições de seus países de origem, incluindo a língua, em detrimento de uma unidade nacional, o governo brasileiro instituiu as proibições a respeito do uso de línguas estrangeiras, que ia desde o fechamento de gráficas e jornais que veiculassem textos em línguas estrangeiras, até os níveis mais íntimos da vida privada.

Moser (1998, n.p) aponta que os relatos dos descendentes de imigrantes italianos que viveram o período destacam o medo e a sensação de insegurança constantes:

\begin{abstract}
Em quase todos os depoimentos, foram constantes as declarações que afirmavam que, tanto os agentes da Polícia, quanto os espiões e delatores, invadiam até espaços privados os quais não ofereciam segurança alguma. Todos podiam ser surpreendidos e delatados, a qualquer momento. A presença do medo era total, pois os espiões não só rondavam a casa, mas se escondiam embaixo dela, para surpreender alguém num flagrante.
\end{abstract}

Essas denúncias são representativas dos micropoderes, o Estado não precisa estar presente e intervir diretamente na vida privada das pessoas, ele cria esses inimigos comuns (na época todos os estrangeiros, em SC especialmente os alemães e italianos), os quais são controlados diretamente pelas pessoas próximas, não pelo Estado em si.

Onde há poder, ele se exerce. Ninguém é, propriamente falando, seu titular; e, no entanto, ele sempre se exerce em determinada direção, com uns de um lado e outros do outro; não se sabe ao certo quem o detém; mas se sabe quem não o possui. (FOUCAULT, 2009a, p. 45).

Essa capacidade ubíqua do poder foi colocada a serviço do Estado, durante o período do Estado Novo. Além de divulgar os perigos dos estrangeiros, sobretudo alemães e italianos, os quais comumente viviam em núcleos isolados, o estado rotulou-os como "quinta-coluna":

O termo quinta-coluna foi utilizado exaustivamente pela imprensa para designar os estrangeiros ditos traidores, em nome da segurança nacional. Vargas (re)utilizou o termo e chamou todos os trabalhadores do Brasil à manutenção da ordem no combate ao quinta-colunismo e a vigilância permanente, estimulando o trabalhador ordeiro a participar da defesa da pátria. (SANTOS, 2007, p. 69) 
O que ocorre nesse contexto é uma deflagração ubíqua do poder, que pode ser representada pelo panóptico (FOUCAULT, 1987), o qual pode ser entendido como uma metáfora da sociedade de vigilância. Esse mecanismo é efetivo não por conta da certeza de se estar sendo vigiado, mas justamente pelo fato de não se saber se está sendo vigiado. A ação dessa tecnologia pode explicar o medo que leva os imigrantes a de fato não falarem suas línguas e inclusive se recusarem a ensiná-las a seus filhos; pode ainda ser outra maneira de tornar os corpos dóceis, mais do que obedientes, torná-los úteis para o projeto de nacionalização empreendido pelo Estado.

É assim que o poder exercido pelo Estado tem maior alcance, a ponto de interferir mesmo na esfera privada da vida das pessoas. Para os vizinhos que os denunciam, os imigrantes e seus descendentes não são mais as pessoas que eles conheciam e que falavam com seus filhos em língua materna, eles são reduzidos apenas a uma categoria: estrangeiros inimigos/quintacoluna.

Essa atitude em relação aos imigrantes e seus descendentes é resultado de uma mudança no discurso. Os colonos estrangeiros, eram apresentados como limpos, trabalhadores, religiosos, desenvolvidos. De acordo com Campos (2006), esse teria sido um discurso difundido tanto pelo governo quanto pela elite a fim de justificar a colonização europeia (não-portuguesa) em Santa Catarina: "esse discurso repercutiu significativamente junto aos imigrantes alemães, italianos e seus descendentes, ajudando a valorizar seu trabalho disciplinado frente ao 'caboclo' do litoral ou da praia." (CAMPOS, 2006, p. 47)

A partir desse discurso, em alguma medida se explica o sentimento de superioridade dos imigrantes italianos e seus descendentes em relação aos "brasileiros" ". Soma-se a isso o ideal de italianidade retratado no período da Primeira Guerra ${ }^{7}$, o qual mostrava o italiano como um homem honrado, heroico, decidido a morrer pela pátria, pátria essa que se dizia ser também daqueles que estavam nas Américas, embora muitos tivessem vindo para cá sem a possibilidade de poder voltar ${ }^{8}$.

Mesmo antes das políticas de controle do Estado Novo, o discurso que conferia aos imigrantes italianos superioridade era um instrumento de controle, na medida em que incutialhes o orgulho de serem supostamente melhores que os preguiçosos que viviam no litoral, para que, assim, os italianos seguissem trabalhando mais e melhor, buscando sempre se distanciarem dos caboclos do litoral e estando sempre contentes com isso. De certa forma esse discurso é biopolítico, porque entende o homem como força de trabalho, a partir do corpo, mais do que isso, esse discurso atua como um mecanismo disciplinar para criar corpos dóceis (FOUCAULT, 1987).

Dar aos imigrantes italianos e alemães um status mais alto é um mecanismo para o controle e adestramento dos corpos, "o próprio sistema de classificação vale como recompensa ou punição" (FOUCAULT, 1987, p. 151). Os discursos que se faziam circular sobre os imigrantes italianos e alemães e seus descendentes também construíam uma imagem (um imaginário) para essas categorias.

\footnotetext{
${ }^{6}$ É comum ainda hoje, entre comunidades de descendentes de italianos, o dito "italiani grazie Dio".

${ }^{7}$ Uma vez que o sentimento de pertencimento a uma nação italiana só se consolidou na Itália após a unificação, a identificação dos imigrantes italianos com a nação italiana só aconteceu posteriormente. Houve uma construção de italianidade em SC, processo que ocorreu no início do século XX, sobretudo a partir de alguns jornais italianos, os quais circulavam no estado, que exaltavam figuras heroicas da história italiana e fortificavam o orgulho de ser italiano, referindo-se principalmente à participação da Itália na Primeira Guerra Mundial. (OTTO, 2002)

8 “Alguns passaportes tinham um carimbo de senza ritorno, que quer dizer: sem retorno, ou seja, ficariam em definitivo no país.” (FABRO, 2015, p. 41)
} 
Outro mecanismo de controle importante empreendido pelo Estado Novo foi a escola, a campanha de Nacionalização do Ensino, que incluía desde a criação de escolas até os conteúdos a serem ensinados e o modo como ensiná-los; aliada às leis de nacionalidade, essa campanha foi uma máquina de produzir corpos dóceis. De acordo com Fabro,

[...] "o estrangeiro" que veio para cá iludido pelas promessas vãs da terra de cucagna, foi transformado pelo Estado-Nação brasileiro, em “inimigo público" e, para voltar a "ser aceito", necessitava aprender a língua do hospedeiro e comunicar-se através dela. (FABRO, 2015, p. 80)

No final da década de 1930, houve a centralização do ensino, por parte do Estado, e passou a ser obrigatória a frequência de crianças e jovens na escola, frequência que era fiscalizada por meio dos diretores e professores, os quais deveriam informar ao governo os nomes das famílias que não estivessem matriculando ou mantendo seus filhos na escola. A frequência das crianças na escola era inclusive condição para que as famílias pudessem ter acesso a serviços públicos (era preciso que as famílias apresentassem um documento expedido pela escola atestando que seus filhos de fato frequentavam a escola pública). De acordo com Campos, foram também estabelecidas multas para as pessoas "que ministrassem o ensino primário ou pré-primário individual ou a domicílio. Qualquer pessoa que cedesse sua residência para esse fim estaria sujeita à mesma penalidade." (SANTA CATARINA, 1939, p. 105). Sendo assim,

[...] com o objetivo de legitimar seu poder, o Estado-nação utilizou a escola e os meios de comunicação para moldar e formar cidadãos que, obedientes e calados, deveriam seguir as "ordens" emanadas dos governantes, como acontecido no processo de unificação da língua nacional brasileira. (FABRO, 2015, p. 63)

A educação passa a ser também uma ferramenta de controle sobre os corpos dos imigrantes e seus descendentes: não apenas por ser uma educação preocupada em atender aos interesses nacionalistas do Estado Novo, mas também porque é usada como moeda de troca para se ter acesso aos serviços públicos.

Ainda seguindo Fabro, a experiência da escola foi traumática para os filhos de imigrantes italianos durante o período do Estado Novo, em especial depois de o Brasil ter declarado guerra ao Eixo, em 1942; além de sofrerem com a espionagem dos vizinhos em suas casas, nas escolas as crianças sofriam inclusive castigos corporais quando usavam alguma palavra em língua estrangeira:

[...] a perda/supressão do ensino da língua materna/italiana falada/escrita pelos considerados estrangeiros, descendentes de italianos e de outras etnias, reverberou de modo violento (coerção física e simbólica), atingindo, principalmente, os falantes do sul. (FABRO, 2015, p. 60)

Grande parte das políticas destacadas neste estudo passam pela questão linguística, porque é principalmente pela língua que se estabelece quem é estrangeiro ou imigrante, é também por uma normatização da língua que a radiodifusão entra em cena. Nesse cenário a língua é entendida como fator identitário essencial: é proibindo a língua estrangeira que serão cortados todos os vínculos com a pátria de origem; é também promovendo a língua nacional que se vai constituir um ideal uno e coeso de nação. No caso dos imigrantes italianos, especificamente, os quais trouxeram para o Brasil uma língua sem pátria (não falavam a língua italiana oficial), buscaram aqui, por meio da língua, estabelecer relações com suas origens, para 
em seguida, ainda por meio da língua (dessa vez a língua portuguesa), abandonar sua pátria, a qual apenas à distância adquiriram.

\section{CONSIDERAÇÕES FINAIS}

Após a discussão, à luz da biopolítica, de várias políticas do Estado Novo que incidiram sobre a língua e os imigrantes, é possível perceber uma espécie de sequência de ações: intensificação do controle sobre a sociedade (por meio de leis e normas ${ }^{9}$ ), seguido pela racialização e a criação de um inimigo comum (uma ameaça), a centralização da informação e a difusão de uma suposta hegemonia. No caso das políticas do Estado Novo, todas essas ações passavam em alguma medida pela língua, que pode ser entendida como um mecanismo de poder.

As consequências das políticas do Estado Novo para os imigrantes e seus descendentes, mais especificamente os italianos, também passam pela questão linguística: as línguas italianas deixaram de ser faladas, tanto em esfera pública quanto privada; desenvolveuse entre descendentes de italianos a vergonha da sua língua (ou línguas). De acordo com Torquato,

[...] destituídos do direito de falar a própria língua, obrigados a vivenciar o apagamento de sua cultura e de sua ancestralidade, os imigrantes foram desapropriados de si. A língua que antes era materna, da aceitação, do acolhimento, da memória e da identidade, agora era a língua que causava discriminação, exclusão, violência e humilhação. (TORQUATO, 2017, p. 23)

Além do apagamento das várias línguas italianas trazidas pelos imigrantes, o termo "colono", que no início do século XX era usado para designar os imigrantes europeus que vieram colonizar o Brasil, adquiriu conotação negativa, sendo hoje usado pejorativamente para se referir aos descendentes de italianos, sobretudo, que vivem em pequenas cidades ou zonas rurais. O que também é resultado de um processo que teve início com as políticas do Estado Novo, quando o "colono" passou a ser aquele que fala errado, trabalhador rural que vive isolado.

Ainda hoje, entre os descendentes de italianos muitas vezes se manifesta a vergonha da língua italiana (não só das línguas que trouxeram seus antepassados, mas também da língua italiana standard, a qual é ensinada em algumas escolas de Santa Catarina):

A perseguição a estes colonos por motivos de uso do dialeto italiano, representou acima de tudo violência: mortificação do eu, dor, humilhação, desprezo, incompreensão e injustiça, e acima de tudo, a introjeção do medo e da vergonha de se falar a língua de suas origens étnicas. (TORQUATO, 2017)

De acordo com Torquato (2017), é comum entre os adolescentes o discurso de que não querem aprender o italiano por ser uma língua de "colono", de gente da "roça", embora o italiano standard não seja a língua do nonno e da nonna (nos casos em que algo das línguas italianas dos imigrantes tenha sido preservado).

Sabendo que as relações de poder não são unidirecionais, cumpre ressaltar, no entanto, que houve, por parte dos imigrantes e seus descendentes, resistências às imposições de controle, enfrentamento do biopoder exercido pelas políticas linguísticas do Estado Novo. Essa resistência se manifesta, entre outras meios, pela manutenção, em alguns municípios com

\footnotetext{
${ }^{9}$ Não era uma lei que determinava que aqueles que se opunham ao projeto de nacionalização fossem chamados de "quinta-coluna", no entanto foi uma norma que se estabeleceu e serviu para alimentar um mecanismo de vigilância que atendesse aos interesses do Estado.
} 
histórico de imigração marcadamente italiana, de festas, monumentos, e até do orgulho de ser italiano (italiani grazie Dio). Ademais, apesar de proibições legais e sociais, descendentes de imigrantes continuaram a utilizar as línguas de seus antepassados, as quais se fazem presentes ainda hoje em municípios fundados por imigrantes, manifestas, por exemplo, nas leis municipais que inserem no currículo das escolas o ensino de italiano. O estudo desses mecanismos de resistência, no entanto, não era o propósito deste artigo, mas merece uma pesquisa futura.

\section{REFERÊNCIAS}

CAMPOS, Cynthia Machado. A política da língua na era Vargas: proibições do falar alemão e resistências no Sul do Brasil. Campinas, SP: Editora da UNICAMP, 2006.

FABRO, Maristela Fatima. Trajetórias de Uma Língua (Mal)Dita: supressão, legalidade e emergência do ensino da língua italiana nas escolas públicas de Santa Catarina (1996-2012). Tese - Universidade Federal de Santa Catarina, Centro de Filosofia e Ciências Humanas. Programa de Pós-Graduação em Sociologia Política. Florianópolis, SC, 2015. 532 p.

FOUCAULT, Michel. Aula de 17 de marro de 1976. In: FOUCAULT, Michel. Em defesa da sociedade - curso no Collège de France, 1975-1976. Trad. Maria Ermantina Galvão. São Paulo: Martins Fontes, 2005.

FOUCAULT, Michel. Os intelectuais e o poder. In: FOUCAULT, Michel. Microfísica do poder. Trad. Roberto Machado. 27. ed. Rio de Janeiro, Graal, 2009a.

FOUCAULT, Michel. Governamentabilidade. In: FOUCAULT, Michel. Microfísica do poder. Trad. Roberto Machado. 27. ed. Rio de Janeiro, Graal, $2009 \mathrm{~b}$.

FOUCAULT, Michel. Vigiar e punir: nascimento da prisão. Trad. Raquel Ramalhete. Petrópolis, RJ: Vozes, 1987.

MOSER, Anita. A violência do Estado Novo Brasileiro contra os colonos descendentes de imigrantes italianos em Santa Catarina durante a Segunda Guerra Mundial. In: CELI, S. (Org.). Quaderni dell'ADREV 4. Ravenna: Angelo Longi Editori, 1998.

OTTO, Claricia. Avanti, cari connaionali! Tentativas de construção da italianidade em Santa Catarina. Esboços, v.10, n. 10, pp 119-134, 2002. Disponível em: https://periodicos.ufsc.br/index.php/esbocos/article/view/391/9857. Acesso em: 27 jan. 2019.

SANTA CATARINA. Decreto-Lei n ${ }^{\circ}$ 301, de 24 de fevereiro de 1939, que estabelece normas para a obrigatoriedade do ensino primário, institui a quitação escolar e cria o registro do censo escolar. Coleção de decretos-leis de 1939. Florianópolis: Imprensa Oficial, 1939. 272 p.

SANTOS, Fabiane dos. A construção do inimigo: é tempo de guerra, medo e silêncio. Revista Santa Catarina em História, v.1, n. 2, pp. 62-72, 2007. Disponível em: http://seer.cfh.ufsc.br/index.php/sceh/article/view/34. Acesso 27 jan. 2019. 
TORQUATO, Carolina Pizzolo. O italiano na escola pública: conflitos históricos em Santa Catarina. Revista de Italianística, n. 35, pp. 15-28, 2017. Disponível em: http://www.revistas.usp.br/italianistica/article/view/141889. Acesso em: 27 jan. 2019.

VIRTUOSO, Tatiane dos Santos.; RABELO, Giani. Escolas étnicas italianas: Urussanga como principal centro ítalo-brasileiro catarinense no início do século XX. Acta Scientiarum. Education., v. 37, n. 1, pp. 65-77, 2015. Disponível em: http://periodicos.uem.br/ojs/index.php/ActaSciEduc/article/view/22261/pdf_28. Acesso em: 17/04/2019.

Recebido em: 30 de janeiro de 2020 Aceito em: 13 de abril de 2020 Publicado em Maio de 2020 